\title{
IT Consultants in Acquisition IT Integration
}

\section{A Resource-Based View}

\author{
Henningsson, Stefan; Øhrgaard, Christian
}

Document Version

Accepted author manuscript

Published in:

Business \& Information Systems Engineering

DOI:

10.1007/s12599-016-0433-5

Publication date:

2016

License

Unspecified

Citation for published version (APA):

Henningsson, S., \& Øhrgaard, C. (2016). IT Consultants in Acquisition IT Integration: A Resource-Based View. Business \& Information Systems Engineering, 58(3), 193-212. https://doi.org/10.1007/s12599-016-0433-5

Link to publication in CBS Research Portal

\section{General rights}

Copyright and moral rights for the publications made accessible in the public portal are retained by the authors and/or other copyright owners and it is a condition of accessing publications that users recognise and abide by the legal requirements associated with these rights.

Take down policy

If you believe that this document breaches copyright please contact us (research.lib@cbs.dk) providing details, and we will remove access to the work immediately and investigate your claim. 


\section{IT Consultants in Acquisition IT Integration: A Resource-Based View}

\section{Stefan Henningsson and Christian Ohrgaard}

Journal article (Post print version)

Cite: IT Consultants in Acquisition IT Integration : A Resource-Based View. / Henningsson, Stefan; Ohrgaard, Christian. In: Business \& Information Systems Engineering, Vol. 58, №. 3, 2016, p. 193-212.

The final publication is available at Springer via http://dx.doi.org/10.1007/s12599-016-0433-5

Uploaded to Research@CBS: September २016 


\title{
Consultants In Acquisition IT Integration: A Resource-Based View
}

\author{
Stefan Henningsson \\ Copenhagen Business School \\ sh.itm@cbs.dk
}

Christian Øhrgaard

Semmle Limited

c@change.dk

\begin{abstract}
Increasingly, companies are drawing on capacities provided by external consultants to design and execute strategic IT initiatives. However, despite evidence of the impact of such services on IT performance, little is still known about the roles external consultants serve in relation to specific strategic IT initiatives and how companies can draw effectively on their services. This paper investigates the use of consultants in relation to one type of major strategic IT initiative: acquisition IT integration. Acquisition IT integration, which is the integration of the acquirer's and target's IT following a corporate acquisition, presents a difficult but crucial IT challenge for the many acquiring organizations. Through a comparative case study of four acquirers, theoretically grounded in the resource-based view of the firm, we analyse how acquirers draw on external consultants to realize acquisition IT integration. We identify two complementary and two supplementary roles consultants assume in these projects. Additionally, we identify three characteristics of the acquisition IT integration strategy that influence how the acquirers assign different roles to IT consultants. The resulting model, depicting the use of external consultants in acquisition IT integration, contributes to the literature on acquisition IT integration by providing an explanation for IT-based value creation in acquisition that is rooted in the external of the acquirer. In addition to adding to the limited, but highly relevant, extant literature on acquisition IT integration, the study also provides general insights into the use of consultants to address strategic IT initiatives.
\end{abstract}

Keywords: acquisition, merger, IT integration, consultants, resource-based view

\section{Introduction}

External consultants have come to play a critical role in the shaping of IT strategies (Bradshaw et al. 2015; Chang et al. 2013; Bradshaw et al. 2012). In 2014, the global market for IT consulting was valued at $\$ 48.2$ billion (KCRA, 2015). Most companies rely on the capacities of external consultants for assistance when embarking on IT projects of significance to the organization (Finney and Corbett 2007; Ko et al. 2005). The relative contribution that such consultants make is determinant for the outcomes of the IT initiatives. Studies have generally found that the relationship with external sources of competence is one key determinant for a positive impact of IT investments on firm performance (for reviews, see Wade and Hulland 2004; Premkumar 2003). For example, in an ERP context, high-quality external competence has been found to be among the 
Pre-edited version of Henningsson \& Øhrgaard: "Consultants In Acquisition IT Integration: A Resource-Based View". Paper forthcoming in Business \& Information Systems Engineering. Refer to the published journal version for citations.

most significant determinants for the benefits extracted from ERP adoption, implementation and use (Ifinedo 2008; Thong et al. 1994; Wang and Chen 2006; Lech 2013).

However, despite the important contribution of external consultants to the shaping of strategic IT initiatives, explanations of the roles consultants serve in relation to specific strategic IT initiatives and how organizations can draw most effectively on the capacities of consultants remain scarce in the literature (Bradshaw et al. 2015; Chang et al. 2013; Bradshaw et al. 2012).

In this paper, we focus on the use of external consultants in one particular strategic IT initiative: the IT integration of corporate acquisitions. Acquisitions are used as strategic means for companies to create value through economies of scale and scope, by securing access to important technologies, or through enabling future growth options (Haleblian et al. 2009; Hitt et al. 2009). While these acquisitions are frequently beneficial to the owners of the acquisition target, evidence shows that acquirers' average returns (in either financial or accounting terms) are not statistically distinguishable from zero (Kengelbach et al. 2011). However, there is important variance around the mean of zero value creation. While some acquisitions lead to notable value creation for the acquirer, others lead to value destruction. Despite much academic attention (see, for example, Barkema and Schijven 2008 for an extensive review), the variance around the mean is still much in need of both theoretical and empirical work.

The integration of the acquirer's and target's IT resources (henceforth referred to as acquisition IT integration) is considered important for explaining value creating acquisitions (Tanriverdi and Uysal 2013; Tanriverdi and Uysal 2011; Henningsson 2015). The role of IT integration in acquisitions is generally attributed to IT integration being a prerequisite for operational integration (e.g. Mehta and Hirschheim 2007; Wijnhoven et al. 2006; Yetton et al. 2013; Toppenberg and Henningsson 2014). Some 45-60\% of the expected benefits from acquisitions are said to be directly dependent on the integration of IT systems (Accenture 2005; Sarrazin and West 2011). Since IT integration has been reported as the third most cited reason for acquisition failure (Rodgers 2005), problems associated with IT integration constitute an important part of the explanation of acquisition performance variations.

Consequently, an emerging literature investigates what makes an acquirer able to manage the acquisition IT integration challenge. In this stream of research, Henningsson and Yetton (2011) investigated how the initial IT conditions of the acquirer and target affect the challenge. Tanriverdi and Uysal (2011) found that acquirers that are generally more successful in cross-business IT integration are also more successful in acquisition IT integration. Tanriverdi and Uysal (2013) concluded that not all of the acquirer's IT resources could easily be extended to support the target acquisition, thereby limiting synergy realization. Finally, Henningsson (2015) investigated how a successful acquirer built knowledge for IT integration through accumulation of experiences to design and implement the acquisition IT integration project.

However, this literature exclusively searches for an explanation of effective acquisition IT integration in the internal capabilities of the acquirer. Indicative evidence suggests that a large proportion of all acquirers are heavily dependent on consultants in the planning and/or execution of acquisition IT integration (Accenture 2002; Freitag et al. 2010; Wirz and Lusti 2004). It is proposed that consultants may contribute essential knowledge through the processes of vicarious learning by transferring experience from one acquirer to the next as best practice (Ko et al. 2005). It has, however, also been proposed that such temporary consultants are badly suited to acquisition IT integration, as they typically do not possess a deep understanding of either the acquirer's or the target's IT (Henningsson 2015).

While the extant literature is occupied with the internal capabilities of the acquirer, this article investigates the use of external consultants as an explanation of effective 
acquisition IT integration grounded in the external capabilities of the acquirer. Because of the limited knowledge about how external consultants contribute to an organization's strategic IT initiatives in general, and about how they contribute to acquisition IT integration in particular, this article takes an inductive approach to exploring the roles of consultants. Our research objective, then, is to develop an empirically based understanding of how external consultants contribute to the acquisition IT integration project. With this objective in mind, we hope to (a) develop a framework that captures the different roles external consultants assume in acquisition IT integration, and (b) unearth how the use of consultants relates to the acquisition IT integration strategy.

To achieve this, we adopt the resource-based view of the firm (RBV) as a general theoretical perspective to develop our descriptive framework. The RBV (Peteraf 1993; Grant 2002) has a proven track record in the IT literature in explaining how IT resources contribute to business value (Wade and Hulland 2004) and how acquisitions create value for the acquirer (e.g. Capron et al. 1998). Resources are the assets that a business owns or can access, including external consultants who can be sourced when needed (Capron et al. 1998; Grant 2002).

Drawing on the RBV, we attempt to accomplish our research objective through a multicase analysis of how four serial acquirers (BeerCo, FoodCo, PumpCo and EngineerCo) draw on external consultants in attending to IT integration in their acquisitions. Through this study we identify four different roles consultants play in the companies' acquisition IT integration projects. We also identify three characteristics of the acquirers' IT integration strategies that influence how the respective companies balance the use of internal and external resources in the integration project.

In doing so, our research contributes specifically to the explanation of how acquiring firms successfully attend to the IT integration challenge, as well as more broadly to the knowledge domain of how organizations rely on external consultants to attend to strategic IT initiatives.

\section{Related literature and framework development}

With the argument that the distinction between "mergers" and "acquisitions" is only juridical, previous literature has frequently used the combined terms "merger and acquisition" (M\&A) to refer to organizational combinations (Mehta and Hirschheim 2007; Wijnhoven et al. 2006; Henningsson and Carlsson 2011). However, there is a growing awareness that the transactions studied in the domain of M\&A's are different from an IT perspective (e.g. Yetton et al. 2013; Henningsson 2015). The many acquisitions of relatively small targets that are undertaken yearly by organizations such as Siemens or Cisco are fundamentally different integration projects to the merger of two multi-business organizations (Henningsson and Yetton 2011). In this paper, we use the term "acquisition IT integration" to stress that we are principally interested in the type of organizational transaction where one major organization acquires a minor organization.

In the following, we develop an initial theoretical framework for studying the use of IT consultants in acquisition IT integration. We start by briefly introducing the RBV on acquisitions. Subsequently, we review the literature on acquisition IT integration from a resource-based perspective. This review identifies two general acquisition IT integration capabilities: design and implementation. We thereafter integrate the reviewed literature with the limited previous research on the use of IT consultants in IT projects. Previous research on the use of IT consultants identifies the complementary and supplementary use of IT consultants. By integrating these reviews we derive a preliminary theoretical framework to guide further investigation. 


\subsection{The RBV on acquisitions}

The resource-based view of the firm (See, for example, Barney 1991; Grant 1991; Peteraf 1993) posits that firms compete on the basis of distinctive resources that are valuable, rare, difficult to imitate, and non-substitutable by other resources. A firm with such organizational resources can enjoy superior long-term performance. Resources are assets and capabilities that are available and useful in detecting and responding to market opportunities or threats (Sanchez and Mahoney 1996). Assets are defined as anything tangible or intangible the firm can use in its processes for creating, producing and/or offering its products (goods or services) to a market (Wade and Hulland 2004; Capron et al. 1998; Grant 2002). An organizational capability is defined as the ability to perform an action, using the available resources, for the purpose of achieving a particular end result (Grant 2002).

A number of categorizations of IT resources exist (Wade and Hulland 2004; Ravichandran et al. 2005; Mithas et al. 2011; Ross et al. 1996; e.g. Bharadwaj 2000). Generally, these categorizations emphasize the socio-technical nature of IT resources by differentiating between "technical" IT resources and "social" IT resources. Technical IT resources are referred to as technology assets, components, applications and infrastructure, while social IT resources are mainly referred to as skills, knowledge, operations and human experiences. Following Wade and Hulland (2004), we divide IT resources into IT assets, which are technology-based, and IT capabilities, which are systems-based.

Fundamental to the explanation of IT-based value creation within the RBV is the insight that IT assets, including hardware and software, rarely lead to sustained competitive advantage by themselves. IT assets are the easiest resources for competitors to copy and therefore represent the most fragile source of sustainable competitive advantage for a firm. Instead, IT assets are combined with IT capabilities, including knowledge and management skills, and general organizational resources, which in complex relational patterns form sustained competitive advantage (Mithas et al. 2011).

In this paper, we use the RBV to analyse IT resources in the particular context of acquisitions. Within the RBV, acquisitions are activities in which two organizations' resources and capabilities are combined (Sudarsanam 2003). Value is created by the sharing and transfer of complementary resources between the two organizations to optimize the newly combined business (Capron et al. 1998). Such transfer includes sharing and transfer of IT resources - the acquisition IT integration.

\subsection{Acquisition IT integration}

The broad conclusion of previous research on acquisition IT integration (for overviews, see Toppenberg and Henningsson 2013; Toppenberg and Henningsson 2014) is that the principal role of IT rests in the realization of business benefits (Mehta and Hirschheim 2007; Johnston and Yetton 1996; Wijnhoven et al. 2006; Giacomazzi et al. 1997; Böhm et al. 2011; Henningsson 2007, 2006). To this end, the IT function needs to be successful in two interrelated tasks: the design and implementation of IT integration (Figure 1). "Design" refers here to the assessment of the acquisition's starting conditions and to-be scenario: what resources exist, what the dependence on the target's IT is and what the eventual solutions should look like (Böhm et al. 2011; Merali and McKiernan 1993; Alaranta and Henningsson 2008; Mehta and Hirschheim 2007; Henningsson and Kettinger 2015). "Implementation" refers to the mostly technical work of the IT integration implementation (Stylianou et al. 1996; Wijnhoven et al. 2006; Toppenberg et al. 2015). 


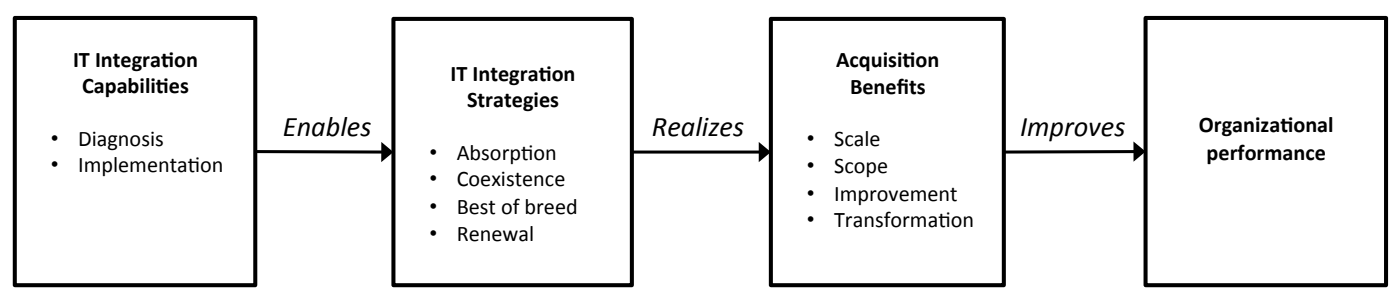

Figure 1. IT-based value creation in acquisitions.

Alaranta and Henningsson $(2007,2008)$ contend that the design of an IT integration strategy should follow a thorough analysis of the synergistic effects expected from the acquisition. The analysis frames the IT integration project, suggesting a path to acquisition IT integration with specific decisions needed to be made based on the initial conditions. Along similar lines, IT integration strategy and acquisition benefits have been described as an alignment process (Mehta and Hirschheim 2007; Johnston and Yetton 1996; Wijnhoven et al. 2006; Giacomazzi et al. 1997; Henningsson and Yetton 2011).

Henningsson and Yetton (2014) outline four strategies for acquisition IT integration:

- In IT absorption, data from the target's IT systems are migrated to the acquirer's IT systems, whereupon the target's IT systems are retired. The strategy is useful when the targets can operate with the acquirer's IT systems without damaging the business and enable business process standardization and cost reduction (Johnston and Yetton 1996; Giacomazzi et al. 1997; Wijnhoven et al. 2006).

- In IT coexistence, IT systems that do not correspond to any system of the acquirer are retained. In full coexistence, all of the target's systems are kept. In partial coexistence, only the target's unique IT systems are retained, while parallel or comparable systems are changed to those of the acquiring organization (Johnston and Yetton 1996).

- IT best of breed is a strategy in which a careful evaluation is made of each of the acquirer's and target's systems to select common systems for the combined organization. This is necessary when the target has some IT systems or IT-based business processes that are superior to the acquirer's systems and processes (Johnston and Yetton 1996; Giacomazzi et al. 1997; Wijnhoven et al. 2006).

- IT renewal is necessary if neither the acquirer's nor the target's IT systems can support the combined organization. This can be the case if the acquisition is made to fundamentally change the acquirer's business strategy. In IT renewal, new IT systems have to be developed (Wijnhoven et al. 2006; Mehta and Hirschheim 2007).

Effective delivery of acquisition IT integration is contingent on the acquirer being able to design and implement an IT integration project with a mixture of IT integration strategies (Henningsson and Yetton 2013). Henningsson (2015) investigates how an acquirer develops design and implementation capabilities. His conclusion is that these abilities have to be built during a series of heterogeneous acquisitions. Repeating the same type of acquisition over and over again may teach the acquirer how to implement IT integration that suits this particular type of acquisition, but variation in experiences is required to gain the expertise to appropriately design IT integration for a range of different scenarios. According to Henningsson (2015), the knowledge necessary to do so is highly tacit and requires in-depth knowledge of the acquirer's IT resources and organizational context. The relevant knowledge therefore has to be built up from experience, rather than sourced from the external of an organization. Henningsson (2015) therefore suggests that temporary IT consultants may be unfit for the task. Yet, they seem to be frequently used in the acquisition IT integration process (Accenture 2002; Freitag et al. 2010; Wirz and Lusti 2004). 


\subsection{IT consultants}

External human resources are employed as agents that perform their work tasks for a client organization (Håkansson and Isidorsson 2012). Since Atkinson's studies of the flexible firm (Atkinson 1985; Atkinson and Meager 1986), the external workforce has been generally perceived as a means of achieving flexibility. (Atkinson and Meager 1986)on identified the external workforce as a secondary group of workers who contributed to numerical flexibility. Using employees on temporary contracts, employers found it easy to adapt staffing levels. The same conception of the external workforce appears in subsequent studies (Kalleberg et al. 2003; Houseman 2003). Numerical flexibility is presented as the opposite to functional flexibility (Kalleberg et al. 2003). Functional flexibility refers to internal flexibility through the design of the organization so that employees can vary their work tasks and participate in decision-making. According to the model of the flexible firm, the combination of functional and numerical flexibility results in core and periphery segmentation (Atkinson 1985; Atkinson and Meager 1986). The core is associated with functional flexibility, upskilling and highperformance work systems. The periphery, on the other hand, is associated with numerical flexibility, deskilling and routine work (Kalleberg et al. 2003).

However, the division into core and periphery has been called into question (Ackroyd 2002; Håkansson and Isidorsson 2012). According to this critique, there is no evident core and periphery segmentation. Thus, when defining agency work, we initially make no distinction as to whether the agency worker contributes towards the periphery or the core of the client organization. Instead, following the RBV, we define IT consultants as human resources (Grant 1991) that can be added from the external resources of the company when needed. Consequently, while some definitions of IT consultants would exclude consultants either giving advice, performing highly skilled tasks or doing mundane everyday tasks, our definition includes consultancy in all these functions. We will return to this initial positioning in the discussion.

In relation to IT and companies' IT functions, two generic roles of IT consultants can be found: the complementary and the supplementary roles (e.g. Sedera and Gable 2010; Ko et al. 2005). Complementary roles tend to be associated with the use of best practice within organizations, and with introducing new knowledge to clients (Sedera and Gable 2010; Davenport 1998). The supplementary role delivers resources similar to those the client already possesses, but answers the need for flexible staffing in times of high demand on the organization (Siakas and Balstrup 2006).

In an ERP context, most companies rely on IT consultants to help in developing and implementing systems (Finney and Corbett 2007; Ko et al. 2005). High-quality external expertise is often seen as the most critical factor in effective ERP implementation (Thong et al. 1994) and the most significant determinant of ERP systems success (Ifinedo 2008). Studies have also found a correlation between the level of external expertise and ERP adoption success (Wang and Chen 2006).

In these studies, the explicit or implicit role assumed by IT consultants is that of the external expert, who contributes expertise not possessed by the client organization. It is expected (with some variations) that external parties bring new knowledge to the software and to "best-practice" business processes (Davenport 1998). The expert agency worker complements the capabilities of the client. The complementary knowledge is gained from experiences in other companies that have faced similar problems. IT consultants thus present the possibility of vicarious learning from others.

Around the mid 1990s, researchers interested in organizational learning began to question the assumption in learning research that firms only learn from their own experiences. Based on the theory of imitation (DiMaggio and Powell 1983) and vicarious learning (Bandura and McClelland 1977), researchers started to explore the possibility that organizations learned from each other. Vicarious learning enables an organization to explore a variety of ways of performing tasks without incurring any costs and risks that 
might be associated with experimenting with alternative actions (Haunschild and Miner 1995). Beckman and Haunschild (2002) use institutional theory from sociology and social learning theory from psychology to argue that organizations can learn to acquire more successfully by tapping into the experience of their network partners, suggesting that vicarious learning from the experiences of partners helps firms to increase the success of their own acquisitions.

When it comes to IT consultants and acquisitions, the role of financial advisors and transactional advisors from investment banks has been the centre of attention (Allen et al. 2004), primarily focusing on the impact they have on the price tag of the target. Lajoux (1998) recognizes the opportunity to utilize IT consultants in acquisition IT integration, stating that "Managers should consider using services of outsiders to compensate for their deficiencies" (p. 50), pointing to expertise and objectivity as benefits that companies can gain from using external resources in planning the integration.

While the presence of vicarious learning effects among acquirers seems well established, research into the mechanisms of vicarious learning is still in an early stage (Barkema and Schijven 2008). Essentially, for vicarious learning to take place there must be a flow of information from one acquirer to another. We argue that, because of the common use of IT consultants in acquisitions, IT consultants can form an "information bridge" that enables the transfer of experiences between acquirers.

The other use of IT consultants in IT organizations is in supplementary roles. Frequently, IT consultants increase staffing in times of great demand for services. In large-scale IT projects, such as ERP implementations, the challenge facing an IT organization is twofold. As well as the project being exploratory, its sheer scale presents a challenge. Retaining an IT organization that could handle peak demand during "normal" operation may not be possible. Hence, many IT organizations opt for flexible staffing solutions that include employing IT consultants to cope with peak demand. It has been argued that IT consultants frequently contribute with more of the same capabilities that the client already possesses, rather than providing the client with new knowledge (see, for example, Westrup and Knight 2000; Wang and Chen 2006).

This role of IT consultants is also discussed in the outsourcing literature in what is sometimes called "insourcing", here referring to bringing people into the organization in order to meet certain requirements and activities within a specific deadline (Siakas and Balstrup 2006). Quélin and Duhamel (2003) find that one of the key motives for clients to outsource a part of their business is the opportunity to use external resources that will help them overcome a peak demand for services.

The needs and consequences of flexible staffing are associated with being adaptable to a changing business environment (Bouncken et al. 2012; Kalleberg et al. 2003). The consequences of flexible staffing involve important human aspects of work security for the individual worker (Houseman 2003), but there are also consequences for the client organization (Kalleberg et al. 2003). The common norm is to use temporary workers for well-defined tasks that require little independent thinking (Håkansson and Isidorsson 2012). The external workforce is normally not seen as being equally knowledgeable about the client organization that they are expected to develop and design strategies for. Instead, they are seen as better suited to the execution of plans (Bouncken et al. 2012). The difficulty of the tasks to be performed by external workers influences their performance, making general IT consultants better suited to simple tasks with low qualification requirements (Bouncken et al. 2013).

Knowledge retention is seen as a general problem with the use of consultants. The knowledge gained by temporary workers is not retained in the organization (Bouncken et al. 2013). If combined with Henningsson's (2015) conclusion that acquisition of IT integration has to be experienced to be learned, this seems a reasonable consequence of high dependence on IT consultants for acquisition IT integration. 


\subsection{Initial theoretical framework}

Figure 2 outlines our integrated theoretical pre-understanding of how external consultants are positioned relative to the post-acquisition IT integration challenge. Acquisitions can be understood as a combination of two resource bundles into one (Wernerfelt 1984). Following the RBV, value is created in acquisitions by the sharing and transfer of complementary resources between two organizations (Capron et al. 1998). Combining resources can generate benefits of scale, scope, transformation and strategic renewal (Haleblian et al. 2009).

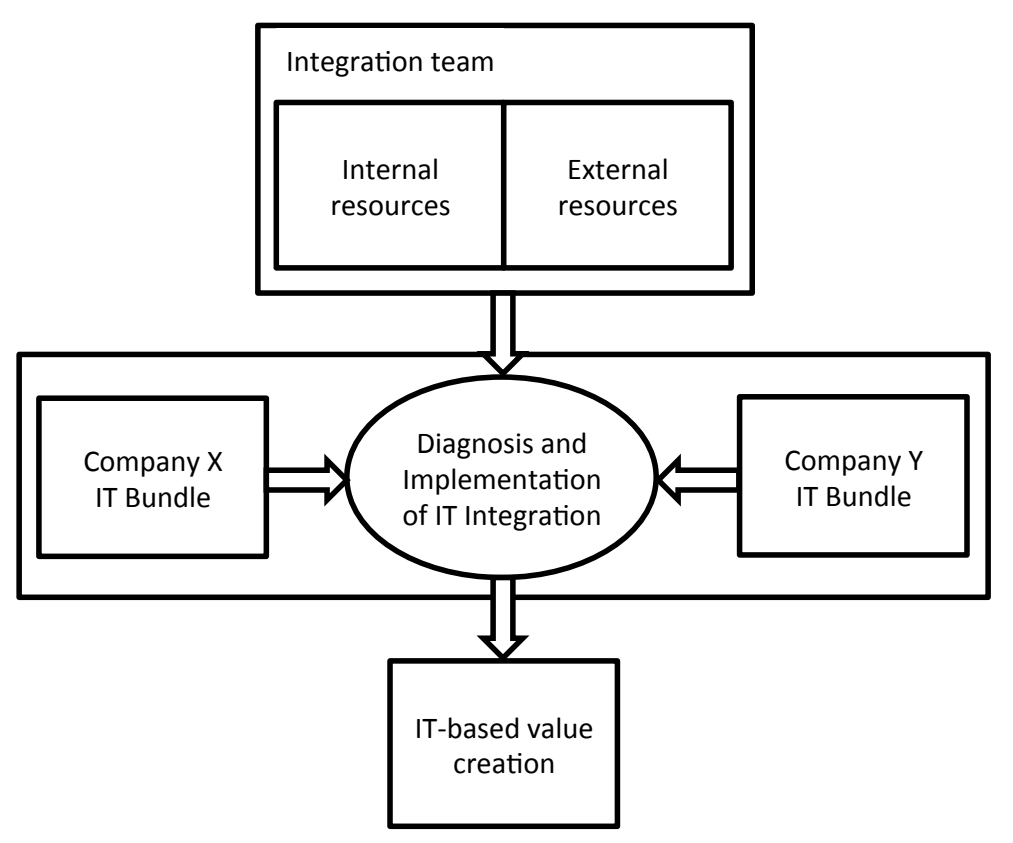

Figure 2. Literature-based pre-understanding of the contribution of external consultants to the acquisition IT integration project.

The actual combination of IT resources occurs in the acquisition IT integration, which can be decomposed into two broad tasks: the IT integration design, in which an IT integration strategy matching the potential of the acquisition is developed, and the implementation, in which the IT integration strategy is executed.

Design and implementation is the responsibility of the IT integration team (DePamphilis 2010). This team consists of internal capabilities from the acquirer and the acquired company (Zollo and Singh 2004) and, in most cases, external consultants (Wirz and Lusti2004; Freitag et al. 2010; Accenture 2002).

In the next section, we provide a brief overview of our research setting and discuss our adopted methodology. However, before proceeding, we would like to clarify that the spirit of our study is one of discovery; our objective was not to deductively test the theoretical framework set up in Figure 2. Rather, this section should be perceived as an expression of our theoretical sensitivity. It provided us with a legitimate frame and potentially useful vocabulary to anchor our findings without straying in different directions. 


\section{Method}

The research presented in this paper follows a comparative case study approach (Eisenhardt 1989; Yin 1994), with the purpose of developing explanatory theory (see, for example, Gregor 2006) for how the use of external resources in the form of IT consultants contribute to the acquirer's IT integration ability.

\subsection{Research context and case selection}

Our comparative case study approach may be characterized as "revelatory" (Yin 1994). Recognizing the paucity of in-depth field studies on the use of IT consultants in general and on the use of consultants for post-acquisition IT integration in particular, our strategy was to study examples of IT consultancy use to derive a richer understanding of the phenomenon.

Our comparative case study was based on a positivist philosophical approach (Dubé and Paré 2003). The positivist approach, in which we examine a set of predefined propositions (Dubé and Paré 2003; Yin 1984), is different from critical or interpretive case study research, where the objective is social critique or understanding the social construction of reality (Klein and Myers 1999).

Although we accept that the contribution of IT consultants can ultimately be seen as socially constructed, this study frames the roles of IT consultants from a simplified, modest foundationalist (Feldman 2002) view of unmediated experiences of a real world. In modest foundationalism, assumptions are made about the existence of certain key elements that allows for theory building until reasons to challenge these assumptions are found. For this study, we are assuming that the IT consultants' influence on IT integration abilities can be captured by regarding them as real-world objects.

The multiple-case approach was chosen to combine the case settings' suitability for rich exploration of acquisition IT integration (Carlsson et al. 2011; Henningsson et al. 2010) with the possibility of perceiving converging and diverging patterns across cases (Eisenhardt 1989). The rich data of the case study presented the prospect that additional insights into the relationship between the acquirer's acquisition strategy and the use of IT consultants might be gleaned. In line with the study's exploratory outset, we search for variance in acquirer attributes regarding acquisition experience, types of acquisitions made, IT integration strategies employed, industry and the importance of IT integration for overall acquisition outcome in selecting cases.

In total, four cases were selected to match the need for rich empirical data in the study (Table 1). The selected cases conformed to three criteria: first, they presented extensive use of IT consultants; second, IT consultants were used in distinct ways within the cases; third, the acquirers in the cases presented variance in their acquisition strategies. These conditions we expected to make the cases match the needs for an inductive exploration of the use.

Table 1. Key acquirer data (figures from 2013)

\begin{tabular}{|l|l|l|l|l|}
\hline & BeerCo & FoodCo & PumpCo & EngineerCo \\
\hline Business area & Beer manufacturer & $\begin{array}{l}\text { Food ingredients } \\
\text { developer }\end{array}$ & $\begin{array}{l}\text { Pump } \\
\text { manufacturer }\end{array}$ & $\begin{array}{l}\text { Engineering } \\
\text { equip. } \\
\text { manufacturer }\end{array}$ \\
\hline Employees & 42,000 & 6,800 & 17,900 & 2,300 \\
\hline Turnover & $€ 8900 \mathrm{M}$ & $€ 1800 \mathrm{M}$ & $€ 3000 \mathrm{M}$ & $€ 290 \mathrm{M}$ \\
\hline Customers & End consumer & Food processors & $\begin{array}{l}\text { Industrial } \\
\text { companies }\end{array}$ & $\begin{array}{l}\text { Mechanical } \\
\text { engineering }\end{array}$ \\
\hline
\end{tabular}


Pre-edited version of Henningsson \& Øhrgaard: "Consultants In Acquisition IT Integration: A Resource-Based View". Paper forthcoming in Business \& Information Systems Engineering. Refer to the published journal version for citations.

\begin{tabular}{|c|c|c|c|c|}
\hline & & & & companies \\
\hline $\begin{array}{l}\text { Acquisition } \\
\text { activity }\end{array}$ & Medium & High & High & Low \\
\hline $\begin{array}{l}\text { Acquisition } \\
\text { experiences }\end{array}$ & $\begin{array}{l}\text { Small and large } \\
\text { acquisitions }\end{array}$ & $\begin{array}{l}\text { Small and large } \\
\text { acquisitions }\end{array}$ & Small acquisitions & Merger \\
\hline Interviews & $\begin{array}{l}\mathrm{CIO} 1, \mathrm{CIO} 2, \mathrm{IT} \\
\text { manager }\end{array}$ & $\begin{array}{l}\mathrm{CIO}, \mathrm{CFO}, \mathrm{ERP} \\
\text { manager }\end{array}$ & $\begin{array}{l}\text { CIO, ERP } \\
\text { manager }\end{array}$ & $\begin{array}{l}\text { Integration } \\
\text { manager, IT } \\
\text { manager }\end{array}$ \\
\hline
\end{tabular}

\subsection{Data collection and analysis}

Interviews, listed in Table 1, were the primary method of data collection. Interview subjects in the investigated organizations included general business managers, IT managers and IT employees involved in the IT integration project. Initial interviews were based on a broad framework, but with a particular focus on concepts related to the composition of the IT integration team. Interviews were semi-structured to facilitate the collection of data for both the deductive and inductive analyses (c.f. Eisenhardt 1989). They were recorded and transcribed. Additional data sources were used to complement the interviews and to triangulate findings. Sensitive documents, including due diligence reports, internal evaluations and other strategic documents, were studied at the respective organization's premises. Following Yin (1994), Table 2 summarizes the measures taken to ensure reliability and validity throughout the research process.

Table 2. Measures to ensure research reliability and validity (based on Yin 1994)

\begin{tabular}{|c|c|}
\hline Reliability & Validity \\
\hline Case study protocols & Multiple sources of evidence \\
\hline - List of acquisitions & - Interviews \\
\hline $\begin{array}{l}\text { - Organizational charts with potential } \\
\text { informants }\end{array}$ & - Documents \\
\hline - Interview guide with areas of interest & Establishing chain of evidence \\
\hline - Strategy to allow for new information & - Extended case stories with extensive use of \\
\hline - Strategies for different informant competences & quotes \\
\hline - Risk areas with potential personal interests & $\begin{array}{l}\text { - Key findings of consultants' roles linked to } \\
\text { specific quotes }\end{array}$ \\
\hline Case study database & W of case drafts \\
\hline - Audio recording, transcriptions & Keview or case aralls \\
\hline - Project documentation & employees of the case companies. Feedback \\
\hline - Field notes with potential alternatives & corrected minor misconceptions of use, but \\
\hline - Outcomes of reviews and informal discussions & $\begin{array}{l}\text { supported our conception of how the case } \\
\text { companies used consultants. }\end{array}$ \\
\hline
\end{tabular}

We examined and made sense of our data, guided by the logic of constant comparative analysis to identify initial concepts, to link this evolving set of concepts to higher-level categories, and then to identify potential linkages between the categories as appropriate (Sarker et al. 2001). This meant that a first round of coding was done by simply marking passages in the text where the respondents talked about the tasks IT consultants performed related to their acquisition, and passages indicating the reasons for how consultants were assigned tasks. Subsequently two researchers independently revisited the marked passages with the aim of sorting the different uses into categories. Clustering was done with a constant comparison method (Strauss and Corbin 1990), where each new code was matched with the growing list of outcome codes. Following the constant comparison method, each code was associated with inclusion and exclusion criteria. This 
task was performed by two researchers independently. Intercoder reliability was about $84 \%$. To resolve differences, we reread the cases until consensus on coding was agreed upon. Resolving discrepancies in this way is said to be a "superior way to correct coding mistakes" (Larsson 1993, p. 1521). The process also involved data triangulation across respondents' organizations, and the roles of respondents (Patton 1990). This process led to the discovery of the different uses of IT consultants.

Next, we organized them under the major theoretical categories suggested by our initial framework, and attempted to discern correlational tendencies (c.f. Eisenhardt 1989) between the roles and the companies' acquisition strategies. Once empirical patterns started to emerge, we placed them in the context of the existing literature, as advised by Bryant and Charmaz (Bryant and Charmaz 2007). Based on empirically induced findings and supportive theoretical arguments, the antecedents of the use of IT consultants were derived.

To integrate findings, we developed rich case stories supported by quotes and document references to ensure empirical support for the emerging stories. Here, we also made a first subjective assessment of the extent of use in the categories Low, Medium and High. High represented a situation where the consultants were the dominant actors in this type of task. Low represented a very marginal use. Medium as a category represented a situation where internal staff and IT consultants split the responsibility fairly evenly. These categories should only be seen as indicative, but they were validated and supported as representative categorizations by the interview subjects. The rich cases were shared with employees from the acquirers to get feedback on the representativeness of the findings. This feedback supported our conception of how IT consultants were used, and the antecedents to the use.

\section{Findings: The use of IT consultants}

Details about the case companies, their acquisition strategies and their use of IT consultants can be found in Table 3. All acquirers in the study have a strong reliance on IT consultants as part of their IT integration teams. However, their use varies notably among acquirers.

Table 3. Cross-case comparison of IT consultant use

BeerCo
Acquisition strategy
BeerCo's growth by acquisition strategy has involved 60 acquisitions since 1997 , including that of a
European competitor in 2008 for $\$ 15.3$ bn. More recently, acquisition-based growth has been focused on Asia
and developing markets in India and Eastern Europe. All the acquired companies are breweries, complete
with production and sales organizations. The acquisition motives are to gain market leader positions within
already operating markets, as well as new market entry.
Following the acquisition, excellence programmes are typically executed in the new business units to
optimize the acquired business. Acquisitions are usually integrated as independent business units in the first
phase. This has been the approach since BeerCo started its acquisition programme in the 1990s.
In 2008, BeerCo initiated a business process integration project. In 2011, it was rolled out in the first country.
The purpose of the programme is to integrate the business processes across the business area. With this
project, BeerCo is aiming at performing a pooled integration of all the targets acquired in Europe since the
late 1990s. The pooled IT integration project followed an IT renewal strategy.
Use of IT consultants


BeerCo used IT consultants for a wide variety of tasks during the pooled integration project. Initially it used IT consultants from tier 1 strategic management consultancies for high-level business cases for the project and for identifying synergies. For IT projects within the different business functions, other agent workers were used to identify synergies, assist in IT strategy definition for the area and manage projects. This is, for example, the case with HR application integration and implementation of shared service centres of accounting.

All implementation tasks that can be specified are outsourced to externals based in low-cost countries, where one of the major global IT management and outsourcing providers accounts for the largest share of these tasks. More than 100 IT consultants have been making system configurations, and more than 200 IT consultants from the provider have been assigned to the project, where the provider also participates with project management resources. Externals are not given the economic responsibility of projects, but are however involved in the strategic and tactical IS decisions.

\section{FoodCo}

Acquisition strategy

FoodCo has made 21 acquisitions since 1997 to transform itself from a local industry conglomerate into a global food ingredients producer. Most targets were small, accounting for 50-70 people per acquisition. Two targets stand out as large, path-breaking acquisitions. A California-based biotech producer with 1,300 employees added a new business area to FoodCo, and a French food additives manufacturer, with 900 employees, brought scale to the food ingredients business. Together, these two acquisitions account for $1 / 3$ of FoodCo's business in terms of revenue and employees.

All acquisitions have been integrated into FoodCo following a sequentially executed absorption strategy based on the view that FoodCo is a "true global company". Business processes are not dependent on geographical location or business area, but are streamlined throughout the business units on a global scale resulting in FoodCo being one large entity rather than a conglomerate of smaller entities. The post-acquisition integration on the information systems side follows this approach by pursuing an assimilation strategy for each acquisition.

FoodCo's IT infrastructure is rolled out at the target sites within the first weeks. Before the end of the first quarter, financial data are fed into the corporate data warehouse solution. The business processes, change management activities and ERP integration are finished within 6-12 months. In cases where the new business does not fit into the existing SAP platform due to special requirements, the global template is updated and rolled out across the business.

Use of IT consultants

During acquisition projects, other projects are down-prioritized to allocate resources for the integration. Despite this, about half of all project resources are IT consultants. Within many functionality areas, FoodCo has chosen two different partners, one for specialized tasks and another one for volume tasks, with IT consultants located in the same areas as FoodCo's IT functions, and in low-cost areas, including Brazil, India and China. Specialized IT consultants are normally sourced from small, independent suppliers.

While IT consultants are used for routine and specialized tasks, the company never transfers the final responsibility, and does not outsource project management tasks. IT consultants are not used for more strategic tasks related to the integration strategy either, as the strategy is tested, performed and non-negotiable and the approach is that integration capabilities should be located in-house in FoodCo.

\section{PumpCo}

Acquisition strategy

PumpCo has made 25 acquisitions since 1997. All acquisitions fit into the corporate strategy focusing on the pump sector. Acquisitions are usually small compared to PumpCo, typically with $70-100$ employees. This is because the industry is fragmented and characterized by many small players. The larger acquisitions have been of firms of 200-400 employees.

PumpCo has two integration strategies, the use of which depends on the acquisition rationale. Targets that are acquired to become a part of the PumpCo brand and global organization are referred to as integration businesses. Companies that are acquired for other strategic reasons, such as a market position in low-cost segments, are referred to as separation businesses. Integration businesses follow an absorption strategy, while separation businesses follow a preservation strategy.

Separation businesses are kept intact with their own IT organizations in order to operate and support their own systems. Separation businesses can utilize the group's resources if relevant, but PumpCo's IT 
organization is not responsible for their IT. Integration businesses are eventually integrated with an absorption strategy, however in a non-sequential order. Most often, the acquired companies have local pockets of IT after the integration process, including both hardware and software that are phased out as the company shifts to PumpCo platforms.

Use of IT consultants

Approximately $15 \%$ of the resources in the IT function are IT consultants. External IT consultants are used both to deal with peak demand and to bring specific knowledge to the integration team. PumpCo utilizes IT consultants when no internal IT employees with the same competence are available in-house. This is often the case with project managers and SAP module developers and project managers. Strategic consultants are included in strategic IT projects that have a notable impact on the business. Recently, this has been the case with the design of a new IT architecture and an ongoing demand-planning project. PumpCo has the responsibility of delivering the projects in their portfolio, and generally keeps the responsibility in-house.

Following acquisitions, resource demand is high, and allocating internal IT resources for the integration tasks is prioritized when meeting the new business unit to send a signal of an integrated company as well as appreciation of the acquired business. The internal resources need to be reallocated from their ongoing projects, and mostly IT consultants fill these roles.

\begin{tabular}{|c|}
\hline $\begin{array}{l}\text { EngineerCo } \\
\text { Acquisition strategy }\end{array}$ \\
\hline $\begin{array}{l}\text { EngineerCo was created in } 2008 \text { is a result of the merger between Alpha and Beta. Following the transaction, } \\
\text { Alpha was split into two parts. One part, the moulding business, was kept as a strategic business unit. The } \\
\text { other part, the surface preparation part, was merged with Beta. EngineerCo was established as a common } \\
\text { group function. In the merger, Alpha retained its pre-merger IT. In Beta, the overall IT integration strategy } \\
\text { was absorption, with elements of best of breed to preserve some of the superior business processes in the } \\
\text { transferred business. Due to the dominant market position gained by Beta, the German competitive authority } \\
\text { imposed on EngineerCo to divest some of their business, for the merger to be approved. This resulted in the } \\
\text { divestment of one Italian and two German business units. }\end{array}$ \\
\hline $\begin{array}{l}\text { The integration plan focused on first identifying and harvesting the "lowest hanging fruits" in terms of } \\
\text { eliminating redundant functions, moving labour from high-cost to low-cost markets, and thus focused on cost } \\
\text { synergies that also affected the IT side. The next level of integration included a shift to one common business } \\
\text { model and one common IT platform to support this. The merging businesses from Beta and Alpha were both } \\
\text { using AX ERP systems, which were highly customized, supporting different business processes. The AX } \\
\text { systems were shifted to Beta's installation, following an absorption strategy, though expanding the } \\
\text { functionality of the system, and making further customizations. } \\
\text { Use of IT consultants }\end{array}$ \\
\hline $\begin{array}{l}\text { mpetencies within operation and su } \\
\text { n consists of about } 50 \text { people who } \\
\text { aving competencies in the IT un } \\
\text { and more technical insights in thei }\end{array}$ \\
\hline $\begin{array}{l}\text { cquisition, a } \\
\text { Consultants }\end{array}$ \\
\hline $\begin{array}{l}\text { As the move to one AX ERP system was carried out, external IT consultants were } \\
\text { assignments and configurations of the system, as the in-house IT competencies did not inc } \\
\text { on the platform. The data migration from one platform to another was handled internally, a } \\
\text { driven in-house. In addition, consultants were used to make an assessment of the ERP syst }\end{array}$ \\
\hline
\end{tabular}

We present our findings related to the use of IT consultants in post-acquisition IT integration in two parts. We first outline our findings related to the roles of consultants in the four investigated organizations. Here, we identify four different roles, two supplementary (Muscle and Expertise) and two complementary (Craft and Brain). Subsequently, we present our findings relative to the positioning of consultancy use respective to the acquirers' IT integration strategies. Our analysis reveals three important influencers of IT consultancy use: temporal organization, acquisition recurrence and integration specificness. Figure 3 graphically depicts the emergent view of how acquirers 
draw on IT consultants as external resources for IT-based value creation in acquisitions. Next, we motivate and explain the components of this model.

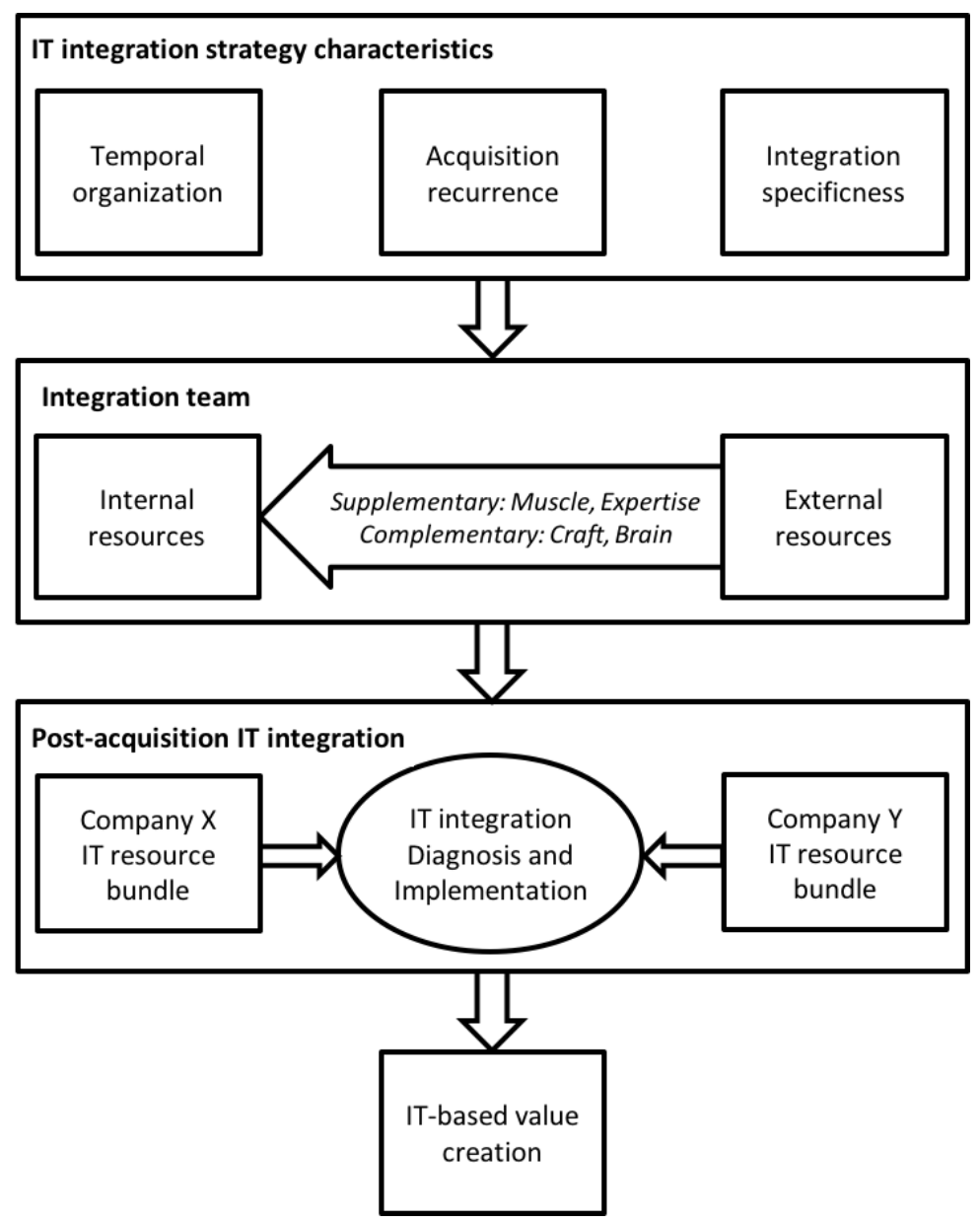

Figure 3. A model of IT consultancy use for IT-based value creation in acquisitions.

\subsection{The roles of consultants}

We found consultants contributing to the acquisition IT integration project in four different roles: Brain, Expert, Craft and Muscle. These roles can be distinguished by how they position themselves relative to (a) the tasks of the acquisition IT integration project, and (b) the distinction between complementary and supplementary resources (Table 4). Within the acquisition IT integration design, the consultants assume the complementary role of Brain or the supplementary role of Expert. Within the acquisition IT integration implementation, consultants assume the complementary role of Craft and the supplementary role of Muscle. We note that our claim is not that these roles are completely independent of each other, but rather that they represent qualitatively distinct patterns, with different dynamics and implications for practice.

Table 4. Four roles of IT consultants in acquisition IT integration

\begin{tabular}{|l|l|l|}
\hline & Supplement & Complement \\
\hline Implement & Muscle & Craft \\
\hline Design & Expert & Brain \\
\hline
\end{tabular}


Table 5 presents an overview of the presence of these roles the investigated acquirers use. This positioning of roles is relative to the acquirer's internal resources. When an IT consultant performs a task for one acquirer, this might be in a supplementary role, while performing the same task in another company might be in a complementary role. This perspective helps describe how IT consultants are used across companies beyond the specific task performed.

Table 5. Cross-case comparison of agency worker use

\begin{tabular}{|c|c|c|c|c|}
\hline & BeerCo & FoodCo & PumpCo & EngineerCo \\
\hline Muscle & $\begin{array}{l}\text { High } \\
\text { Large base of externals } \\
\text { working with system } \\
\text { configurations and } \\
\text { defined } \\
\text { implementation tasks. }\end{array}$ & $\begin{array}{l}\text { High } \\
\text { Widely used in } \\
\text { integration projects for } \\
\text { standardized tasks. } \\
\text { Especially in low-cost } \\
\text { markets. }\end{array}$ & $\begin{array}{l}\frac{\text { High }}{\text { Frequently performing }} \\
\text { operational or } \\
\text { predefined tasks. }\end{array}$ & $\begin{array}{l}\frac{\text { Low }}{\text { Not used as muscle - }} \\
\text { in-house resources } \\
\text { were used for all tasks } \\
\text { they were capable of. }\end{array}$ \\
\hline Expertise & $\begin{array}{l}\text { High } \\
\text { For project } \\
\text { management, IT } \\
\text { strategy advice. }\end{array}$ & $\begin{array}{l}\text { None } \\
\text { No use due to no- } \\
\text { responsibility } \\
\text { outsourcing policy. }\end{array}$ & $\begin{array}{l}\frac{\text { Medium }}{\text { Limited use of IT }} \\
\text { consultants in an } \\
\text { expertise role. }\end{array}$ & $\begin{array}{l}\text { Medium } \\
\text { Used to make } \\
\text { assessments of the } \\
\text { ERP and assisting in } \\
\text { integration planning. }\end{array}$ \\
\hline Craft & $\begin{array}{l}\text { High } \\
\text { For support of legacy } \\
\text { systems, for less } \\
\text { defined } \\
\text { implementation tasks, } \\
\text { and for project } \\
\text { planning. }\end{array}$ & $\begin{array}{l}\text { High } \\
\text { IT consultants with } \\
\text { specialist knowledge } \\
\text { work within a specific } \\
\text { business process area } \\
\text { of the IT. }\end{array}$ & $\begin{array}{l}\frac{\text { Medium }}{\text { Used project managers }} \\
\text { or specialists where } \\
\text { similar resources are } \\
\text { not internal in the } \\
\text { organization. }\end{array}$ & $\begin{array}{l}\text { High } \\
\text { Used for all } \\
\text { development tasks } \\
\text { related to the ERP, as } \\
\text { well as for other } \\
\text { specialist tasks. }\end{array}$ \\
\hline Brain & $\begin{array}{l}\frac{\text { High }}{\text { Used to develop IT }} \\
\text { strategy, for IT } \\
\text { strategy development } \\
\text { in functional areas, for } \\
\text { sparring, for synergy } \\
\text { validation. }\end{array}$ & $\begin{array}{l}\text { None } \\
\text { No use due to no- } \\
\text { responsibility } \\
\text { outsourcing policy. }\end{array}$ & $\begin{array}{l}\frac{\text { Low }}{\text { Used for strategic IT }} \\
\text { project with business } \\
\text { impact. This is not the } \\
\text { case for acquisition IT } \\
\text { integration. }\end{array}$ & $\begin{array}{l}\text { Medium } \\
\text { Used to define their } \\
\text { new strategy } \\
\text { programme and to } \\
\text { identify how to } \\
\text { achieve the expected } \\
\text { synergies. }\end{array}$ \\
\hline
\end{tabular}

\subsubsection{Muscle}

In three of the cases, IT consultants were involved in performing tasks that the company already had competencies to perform in-house, but with the increased workload during the acquisition were still unable to do. For work in this capacity, we refer to the role of Muscle.

- IT consultants assuming the Muscle role perform implementation tasks that the company can do, but need extra people for due to the integration. This can, for example, involve migration of data or the development of integration points (Freitag et al. 2010).

The use of IT consultants as muscle is driven by the high, temporary resource demands during the integration project. None of the companies have in-house resources dedicated to acquisition integration projects that are not dedicated to other tasks in between the acquisitions. Therefore, most of the companies use supplementary resources in the integration process to meet the resource demand for the rather standardized, predefined and well-documented tasks. In most acquisitions, IT consultants are used for different ERP integration tasks within business process areas, including finance, HR or production or for migration tasks. Furthermore, they are being used for system configurations on 
large-scale projects, where the resource demand is exceptionally high for a limited period of time, or operational tasks.

I assume that my people are engaged; they should be occupied $110 \%$ of the time. So there is a limitation to what new tasks we can assign them. (PumpCo, CIO)

In one company, EngineerCo, consultants were not used in the Muscle role. Here, internal staff were used for all tasks they could possibly carry out. The consequence of this decision was that the IT integration project had to adapt to the capacity of the IT organization - not to the need for integration in the business organization. While this was a more cost-efficient way to implement the project, it also meant a very long IT integration phase.

Interestingly, IT consultants in the Muscle role are used in two different ways. Either they are allocated to the specific IT integration project, forming part of the integration team, or external workers are used to free up internal resources for the integration project. The argument behind substituting internal resources with IT consultants to allocate them to IT integration projects is that the acquirer can then meet the target with its own resources, which can reduce resistance towards change.

The choice between the two approaches is related to the predefinition of an IT integration strategy, i.e. the degree to which the IT strategy differs from one acquisition to another. In the acquisition cases where the IT integration strategy was predictable and not up for discussion, the acquirer used externals for subprojects of the integration, thereby allocating externals directly to the integration team. In cases where the IT integration strategy was not predefined, the acquirer preferred to send internal staff to perform the integration, consequently allocating temporary IT consultants to perform operational tasks.

\subsubsection{Expertise}

In three of the case companies, IT consultants were used for advanced design tasks even when the acquirer had the competence in-house to complete the tasks. We term this role Expertise. In one case the use was extensive, and in two there was a moderate level of use in this capacity. One acquirer, FoodCo, actively resisted using IT consultants in this role.

- IT consultants can be used in the role of Expert when used for high-level tasks that the acquirer already has staff to carry out. This is a response to a need to complete acquisition IT integration within a given time frame, with limited internal resources available to complete the tasks.

The use of IT consultants for added expertise occurs when IT consultants are hired in supplementary roles to perform integration design. IT consultants are being used for expertise tasks to a lesser extent than as muscle or as craft resources. Expertise is utilized as the company uses IT consultants to assist with or facilitate the integration planning or to do project management tasks where the project plans are not predefined, but where the company already has capabilities within the same area.

In the beginning, you need to specify and transform your strategic business case to an operational business case. That requires a great amount of [company] knowledge and it requires some [company] people and some consultants who know [the company]. (CIO, BeerCo)

The tasks performed in the expertise role include high-level project management, project planning sparring where extensive knowledge of the company is required, and objective assessments of business processes or information systems (IS). Large-scale integration subprojects, whose participants mainly consist of IT consultants, are often assigned project managers from the same agency to facilitate the process, despite the fact that the company has capabilities to manage the project with external participants. In some projects related to the acquisition integration of information systems, IT consultants are used for sparring during the design work of the project where they work closely together 
with the company. Finally, IT consultants are used to perform objective assessments of the integration plans or business processes in the company, i.e. to validate the internal assessments made by the company.

\subsubsection{Craft}

The most common use of consultants, across all four case companies, was the use of IT consultants to do specific operational tasks in the implementation that the acquirer did not know how to do. In this Craft role, consultants were brought in to deal with specific implementation challenges that rarely recurred in the company.

- The work of external workers can be considered as Craft when it requires know-how that is not present in the IT organization of the acquirer or the target. When IT consultants are hired for specific ERP implementation tasks that are not standard to the corporation, they are used as Craft.

Craft resources are utilized to perform implementation tasks that the acquirer and the target do not have competencies to perform themselves.

We have used consultants on those areas where we have made some kind of customization because there was a special need, or when we have made modifications to the system. (Integration manager, EngineerCo)

The tasks are often well defined and the project managers are able to specify the work or output that the craft resources are to perform or deliver to a fairly detailed level. IT consultants, in these cases, are used due to their highly specialized knowledge with which they can execute the IT integration strategy of the given acquisition. Companies mostly use craft resources for ERP implementation tasks, within the different processes of the ERP implementation or for the customization or integration of small-scope applications that are locally anchored or heavily modified to fit specific business requirements.

IT consultants as Craft are often sourced locally, being based where they perform the tasks. In many acquisition cases, the targets have legacy applications that cannot be outphased initially, and where integration with a corporate platform, or data integration through interfaces, requires work on the legacy applications. These applications are often local solutions with little or no documentation and are written or documented in local languages or contexts. Therefore local IT consultants are used for support or customization tasks. Furthermore, IT consultants with specialist knowledge within a specific sector, with extensive knowledge of the acquirer or with specialist knowledge within a specific non-standard business process, are more difficult to find and are typically located closer to the business.

\subsubsection{Brain}

With respect to reliance on consultants to actively design the IT integration strategy, the case companies took very different positions. One acquirer almost exclusively relied on consultants in this capacity, while another refuted this use completely. Two acquirers lined up somewhere in the middle of these extremes. We term this use of consultants the Brain role.

- When companies hire IT consultants to act as Brains, they hire them to help the company develop integration strategies or high-level synergy assessment and integration plans that the company could not carry out on its own (Lajoux 1998).

The investigated acquirers use IT consultants in the Brain role so as to facilitate strategy definition related to the integration or to the future IT landscape of the company. IT consultants are given the task of planning the realization of the expected synergies related to the acquisition or outlining opportunities for the newly integrated company. 
Pre-edited version of Henningsson \& Øhrgaard: "Consultants In Acquisition IT Integration: A Resource-Based View". Paper forthcoming in Business \& Information Systems Engineering. Refer to the published journal version for citations.

There are a lot of situations where nobody in the company has tried to do this before. In these cases we have been through a lot of brain drains with externals to get things rolling. (CIO, BeerCo)

IT consultants in the brain role are used for large projects where the outcome may have an impact on a corporate level, through the redesign of existing business processes or the adoption of a new system. Brain capabilities are used both globally and locally. Local IT consultants are used because of their knowledge of the company, typically from other projects. In cases where specific strategic capabilities are needed for the integration, but are not available in the local environment, internationally sourced brain capabilities are typically used.

\subsection{Consultancy use and the relation to the IT integration strategy}

Having identified four roles of IT consultants in acquisition IT integration, we recoded the empirical material to find reasons for the divergence in use. The emerging explanations pointed towards three categories of contextual conditions: temporal organization, knowledge induction and flexible staffing. Temporal organization refers to how the acquirer organizes the IT integration in the temporal space, either as a sequence of a minor project or pooled in a larger project. Knowledge induction refers to drivers for staffing the IT integration that resolves both short-term and long-term knowledge requirements. Flexible staffing relates to the need to balance experience variance with indepth understanding in the acquisition IT integration team.

\subsubsection{Temporal organization: sequential vs. pooled IT integration}

The temporal organization of an acquisition IT integration effort takes into consideration the fact that the IT integration project does not always come immediately after a deal is made, but can also be postponed to be co-located with other IT transformation initiatives. How the acquirer organizes this temporal dimension of acquisition IT integration has implications for the use of temporary IT consultants.

When FoodCo and PumpCo acquire targets, the integration onto the corporate IT platform happens sequentially, due to an IT absorption strategy. In most cases the targets are integrated within a relatively short time frame after the acquisition. The integration project requires more resources than the normal resource level of the companies' IT organizations, of which most are muscle and craft resources due to the limited scope and predefined tasks laid out by the IT integration strategy.

In contrast, BeerCo acquired several companies, leaving the targets as separate business units while keeping their information systems and IT operations intact for years, initially following a coexistence strategy. The integration of the separate SBUs into one unified company is performed via a large project, covering integration of all the targets at once. The pooled integration approach led to a high-complexity project with great demand for resources throughout the integration effort within BeerCo, where there is a high dependency on all four types of temporary IT consultants.

While PumpCo aims to perform acquisition IT integration immediately after the acquisition for integration businesses, the same is not true for what the company refers to as separation businesses, where the IS is initially preserved. However, drivers such as changes to the corporate strategy have the effect that occasionally some companies change status from separation businesses to integration businesses, facilitating integration of the target on the IT level.

The drivers associated with sequential and pooled integration are the need to quickly substantiate IT-dependent acquisition benefits and the avoidance of redundant work, respectively. First, because the full potential of the acquisition cannot be realized without full IT integration (Johnston and Yetton 1996; Henningsson and Carlsson 2011; Tanriverdi and Uysal 2011), the acquirer is driven towards integrating the acquisitions one by one. However, within all acquirers there are IT platform cycles, which means that 
acquirers are recurrently undertaking large platform projects to update their IT platforms (Reynolds and Yetton 2015). As the acquirer is getting closer to such a platform project, the substantial cost of integration is redundant as the acquirer will soon face the task of rolling out another platform to the acquired business. Therefore, there is also a driving force present for postponing and pooling integration.

For the limited period of time where the IT integration work is taking place, the project significantly increases the need for personnel. The size of this demand peak, i.e. the need for temporary resources to perform the acquisition integration alongside with daily operations, depends on the nature of the acquisition act and the integration strategy, and thereby on the scope of the integration project. For the pooled IT integration project, the peak in demand is much more significant. This, then, has an impact on the extent of use of IT consultants in supplementary roles. Simply because of the comparatively higher peak demand, the pooled IT integration requires a more extensive use of IT consultants in supplementary roles.

Interestingly, the four case companies deal with resource peak demands caused by acquisition IT integration either by allocating external resources directly to the integration project, or indirectly by allocating them to performing internal operations or participating in other non-integration projects in the IT organization. Direct allocation of IT consultants is the most frequently used method, and occurs when FoodCo uses muscle and craft IT consultants to participate in the integration projects under an internal project manager, when BeerCo sources all four agency worker roles to design, plan and execute the pooled integration project, and when PumpCo directly allocates craft resources to acquisition IT integration projects.

FoodCo, on the other hand, actively down-prioritizes non-integration projects following an acquisition, to free up internal resources to work on the acquisition IT integration. The effect of this approach is the ability of FoodCo to enforce its no-responsibility outsourced policy, even during the resource peaks occurring with integration projects. This allows the company to limit the resource use to the implementation-focused roles of craft and expert resources.

While PumpCo occasionally uses direct allocation when assigning craft resources to integration projects, the company most often uses indirect allocation where internal resources are freed up to participate in IS integration projects by assigning temporary IT consultants to perform the internal resources operational tasks, through the use of IT consultants in the muscle role.

The observation that IT consultants are used to relieve internal resources from their tasks for them to be reallocated to integration projects gives temporary IT consultants a whole new role in the IS integration process. IT consultants can strategically be selected and allocated to where they bring the most value for the company throughout the acquisition IT integration process, which might not be as part of the integration project team. This needs to be considered as companies gain experience from integration projects, as the learning might be different depending on direct or indirect allocation of temporary IT consultants to deal with the resource peak.

\subsubsection{Acquisition recurrence: Induction vs. retention}

For BeerCo and PumpCo acquisition IT integration was perceived as a challenge where they needed knowledge induction from the outside. It has previously been proposed that using IT consultants as a mechanism of vicarious learning is most relevant for the novice acquirer that faces a problem for the first time (Barkema and Schijven 2008). Both BeerCo and PumpCo were experienced acquirers, but still perceived the need for knowledge induction. On the other hand, FoodCo explicitly tried to avoid using IT consultants in any task that had to do directly with the acquisition IT integration. Instead IT consultants were largely used to staff up day-to-day tasks, freeing up internal staff to do the acquisition IT integration. 
Pre-edited version of Henningsson \& Øhrgaard: "Consultants In Acquisition IT Integration: A Resource-Based View". Paper forthcoming in Business \& Information Systems Engineering. Refer to the published journal version for citations.

We never used externals to do the thinking. When we use our own staff in integration, they learn and develop over time. (CIO, FoodCo)

In practice, the need for knowledge induction and knowledge retention becomes at least partially excluding. The learning processes of vicarious learning (Bandura and McClelland 1977) and learning from experience accumulation (Zollo and Singh 2004; Henningsson 2015) have to balance.

For the acquirers in the study, the deciding factor seems to be the extent to which the event is expected to be a repeated action. Despite the fact that BeerCo had made a large amount of acquisitions, the pooled integration project was a one-off time project. Hence, for BeerCo, the need for knowledge induction to overcome the specific challenge at hand was greater than the need for knowledge retention to be able to overcome similar challenges in the future. For FoodCo, acquisitions had become an integrated part of the operation and something that would also be repeated in the future, following a sequential integration approach. Therefore, the need to retain knowledge was more important than the need for knowledge induction. For PumpCo, every acquisition seemed to present new challenges to the acquirer. PumpCo needed both knowledge induction and knowledge retention, to improve and to solve similar problems in the future. Hence, PumpCo aspired to work with mixed teams that could allow for knowledge transfer.

\subsubsection{Integration specificness: Experience variation vs. deep understanding}

Henningsson (2015) concluded that a range of heterogeneous experiences is a prerequisite for the acquirer to be able to accurately design the acquisition IT integration project. With a small or homogenous set of acquisition experiences, the acquirer runs the risk of making errors in the design. IT consultants may have a wide range of acquisition experience and therefore the ability to spot inaccuracies in the IT integration design.

I would like that we had some people here to assist in setting the stage and laying out the strategies. They probably don't have to be there all the way through, but be there to make the strategy for how we integrate this company. People who have tried it before who have tried it 100 times before. That would be super. (CIO, PumpCo)

On the other hand, there is also a great need to understand the acquirer's IT resources in depth to be able to understand the limitations of the resources and to be able to predict how the acquisition will be affected by using the acquirer's IT resources (Mehta and Hirschheim 2007; Yetton et al. 2013).

Every IT set-up is unique. If you come in from the outside, you first have to learn what is unique with this company and how we do business. ... For us, it is incredibly important that we don't make any exceptions to our standardization approach. It will hurt our agility. For other companies, it will not be such a big deal. Those nuances I think are very hard for an outsider to get. (CIO, FoodCo)

Ideally, the acquirer has a knowledge base that is both broad and deep when designing and implementing integration. Frequently, however, that is not the case. Acquirers, including experienced acquirers such as PumpCo, express the need for the increased experience variation that comes with IT consultants.

\section{Discussion and conclusions}

\subsection{Findings}

Investigating the use of consultants in four acquirers' acquisition IT integration projects, we identified two complementary and two supplementary roles that consultants can assume in acquisition IT integration. The complementary roles of Brain and Craft are associated with the carrying out of best practice between organizations, bringing new knowledge to the client organization. The supplementary roles of Expert and Muscle deliver more resources similar to those the client already possesses, but address a need for flexible staffing in times of high demand on the organization. The four roles are combined in a descriptive framework for consultancy use. 
In this study, we also start the process of explaining how the consultancy use related to the acquirers' IT integration strategies. We identify three characteristics that influenced the consultancy use: the temporal organization of the IT integration projects, the recurrence of acquisitions and the need for specificness (as contrasted with applicability of general approaches) in the IT integration project.

First, despite the common conception that acquisition IT integration is of sequential integration, we found examples of when the acquirers had chosen to pool their IT integration project to integrate several acquisitions with one large project. Our data indicates that this timing of the integration project has an impact on the consultancy roles being used, where sequential integration mainly requires the implementation roles of Muscle and Craft, while pooled integration leads to the use of diagnosis roles, including Expert and Brain.

Second, the recurrence of acquisition within the investigated companies influenced the use in that the acquirers that expected acquisition IT integration to be a recurrent challenge for the company hesitated to involve IT consultants in complementary roles. For these acquirers, most prominently exemplified through FoodCo, the competence of acquisition IT integration could not be complementary to the organization. Because acquisition formed part of the growth strategy, the competence needed to support this was business critical and needed to be built in-house. Notably, BeerCo was a serial acquirer that relied heavily on complementary use of IT consultants. This was because BeerCo held the view that the pooled IT integration project would not be a recurrence. We can therefore conclude that there are interaction effects between the different characteristics.

Third, the acquirers' view on how specific their IT set-up and need for IT integration were influenced the use of consultants. This has to do with the trade-off between broad, generic knowledge about IT integration, associated with external IT consultants, and the importance of local knowledge about the acquirers' specific IT set-up and strategies. Valuing the broad knowledge and the need for knowledge induction drives the complementary use of consultants. However, externally sourced IT consultants, it was argued, lack the in-depth knowledge of the acquirer and its IT system necessary to work independently with design tasks.

\subsection{Contributions to theory}

Our paper makes important contributions to the specific literature on acquisition IT integration as well as a broader literature on how companies draw on external resources when attending to strategic IT challenges.

To understand the variation between acquirers in IT-based value creation of acquisitions, previous research has studied acquisition IT integration with a focus on the internal resources of the acquirer (Tanriverdi and Uysal 2013; Henningsson 2015; Benitez-Amado and Ray 2012; Morsell et al. 2009). A major limitation in this literature is that the analysis of how the acquirer attends to the IT integration challenge is limited to internal resources of the acquirer. Evidence from the general IT management literature suggests that the use of external resources, typically sourced as IT consultants, is extensive in these types of strategic initiative and that the use has an important impact on the outcome of the initiative (Bradshaw et al. 2015; Chang et al. 2013; Bradshaw et al. 2012). Our model of the use of IT consultants in acquisition IT integration, depicted in Figure 3, complements extant views by providing a explanation of IT-based value creation that is rooted in the external of the acquirer. It highlights a multifaceted interplay between internal and external human resources that in all the four investigated cases is necessary to bring about acquisition IT integration. It also conveys that this interplay has to be adapted to the specific characteristics of the acquirers' IT integration strategy. These aspects of the IT integration project were previously not recognized in the literature on acquisition IT integration and further our collective understanding of why some acquisition IT integration projects are more effective than others. 
Recognizing the role of external resources in attending to the acquisition IT integration challenge has important implications for how to proceed with research in the different streams of research on acquisition IT integration. One of these streams has tried to link the acquirers' IT integration capabilities to acquisition performance (Tanriverdi and Uysal 2013; Tanriverdi and Uysal 2011; Robbins and Stylianou 1999; Giacomazzi et al. 1997; Weber and Pliskin 1996). Commonly, when operationalizing the concept of IT integration capabilities, these studies measure only the acquirer's internal capacity for integration. Our study suggests that redefining the notion of IT integration capabilities as a function of the resources that the acquirer has access to, as supposed to the resources that can be found within the boundaries of the acquirer, would give a higher precision in models.

Another stream of research investigates how the acquirer builds acquisition IT integration capabilities (Parada et al. 2009; Henningsson 2015). This stream of research, focusing on learning processes such as routine refinement and experience accumulation, implicitly assumes that the acquirer's learning takes place in isolation from the external. Our study contradicts this assumption, suggesting that external IT consultants are an important source of knowledge induction. Looking further into the empirical material of some previously published case studies supports this finding. In both the Danisco case (Yetton et al. 2013) and the Trelleborg case (Henningsson 2015), hiring new IT managers with extensive acquisition experience is mentioned as important events in building the acquirer's IT capabilities. Although this is not exactly the same as employing external consultants, the cases indicate that the view that learning takes place in isolation from the external environment is too simplistic to explain how acquirers build IT integration capabilities. Therefore, future research should continue to explore how the interaction with the external of the company influences the trajectory of the acquirers' IT integration performance over a series of acquisitions. Relevant questions include how different modes of organization of IT consultants (e.g. as independent units or in mixed teams), structures and mechanisms enable or inhibit knowledge induction and retention. It is also relevant to consider how the different approach for IT integration (absorption, coexistence, best of breed and renewal) relates to the use of consultants. Our data did not contain sufficient material clearly pointing in a specific direction as to how the approaches influenced the use. However, we have some indication that the choice of integration strategy has an indirect effect through the three identified characteristics. For example, the pooled integration was associated with a renewal strategy and the sequential integrations with an IT absorption strategy. We can only speculate that this will be a recurrent pattern, and encourage future studies to specifically investigate the validity of the relationship.

Our model can be seen as a substantive theory - a theory developed for a special area of inquiry (as opposed to a general theory with universal application) (Gregor 2006). As such, the dimensions of the model are contextually adapted to particularly meet the IT consultancy use in acquisition IT integration and should not be seen as universally applicable to any IT consultancy use situation. However, by specifically investigating the use of consultants in this domain, we contribute to an understanding of the more general question of how IT consultants can contribute to the performance of strategic IT initiatives.

First, in developing the initial theoretical framework for this study, we tentatively postulated that the established view of the external workforce as a secondary workforce performing tasks of less importance to the focal company was less relevant for our study of IT consultants. Confirming this initial assumption, our study shows that IT consultants do indeed perform work that is both core and peripheral to the company. Therefore, the characterization of the external workforce as a secondary group of employees that only carries out mundane tasks is not applicable in our study. Instead, what seems to be the overarching logic for when assigning works to external consultants are the questions of the recurrence and uniqueness of the challenge at hand. Interestingly, we see that for strategic challenges that the company expect to occur once or at least seldom, the 
willingness to involve consultants in decision-making is extensive. It also corresponds to the resource-based view that the company should build capabilities in areas that can generate a sustainable competitive advantage. A one-off challenge would not generate such an advantage and it does not seem to be of interest to the acquiring companies to build capabilities attending to such a challenge.

This finding that the acquirers extensively draw on IT consultants when addressing what they perceive as one-off challenges is interesting as it may influence how further research investigates the question of how companies learns how to attend to rarely occurring IT challenges. While we know comparatively much about how companies attend to recurrent, operational challenges by building routines and capabilities with reliable performance levels (Miner et al. 2008; Cohen et al. 1996; Cohen and Bacdayan 1994; Cyert and March 1963; March and Simon 1958), we know substantially less about how organizations attend to strategic challenges that happen once in a while and where every instance to some degree is unique (Zollo 2009; Zollo and Winter 2002).

The extensive use of consultants in the companies and the decisive roles they took in our study for rarely occurring decisions showcase how important it is to understand the interplay between the internal and external to conceive of an explanation for how organizations attend to strategic IT challenges. This opens up an important avenue for further research looking at how to weave the company-specific knowledge of the internal with the general knowledge that can be sourced from the external. Such research can both draw on and contribute to the emerging literature on improvisational learning (Miner et al. 2001) and learning sequences (Bingham and Davis 2012).

\subsection{Implications for practice}

We see in our study and from previous research that the use of IT consultants is extensive in strategic IT initiatives as well as influential for the outcome of the initiatives. Therefore, managing the external workforce associated with the initiatives becomes a critical management challenge. Managing consultants means that external consultants need to be coordinated with the internal workforce (Chang et al. 2013), and need to adhere to the general goals of the client organization (Chang et al. 2013). This is potentially difficult as consultants typically can be expected to bring their own agenda associated with specific technologies and the wish to make themselves indispensable (Bloomfield and Danieli 1995). It is therefore critical for the client organization to understand the relative advantages and disadvantages of IT consultants when attending to specific challenges, and to be able to assess the consultants' capacities in relation to the role they are supposed to fill in the project.

Acquiring organizations can use our model when developing strategies for the use of consultants. This includes new uses to reinforce the acquisition IT integration ability, as well as identifying and understanding the consequences of current use. Balancing the drivers and the possible negative impacts of IT consultants requires a careful management of the IT integration team. Kolb and Frohman (1970) suggest that the temporary IT consultants' intervention in the organization should be "directed not only at solving the immediate problem, but also at improving the organization's ability to anticipate and solve similar problems". For this to happen, agency worker use has to be managed in this direction. The investigating acquirers who saw this as a desirable benefit made sure that the IT consultants were engaged in teams, together with employees of the acquirer.

Finally, it has previously been proposed that the use of IT consultants as a mechanism of vicarious learning is most relevant for the novice acquirer who faces a problem for the first time (Barkema and Schijven 2008). Both BeerCo and PumpCo were experienced acquirers, but still perceived the need for knowledge induction. This leads us to suggest that experienced acquirers should also assess the possibilities of using IT consultants for knowledge induction. 


\subsection{Limitations and future research}

Together, the acquisitions performed by the companies in the study represent a diverse base of acquisitions, but this does not provide a sufficient basis to make general statements about the effects of IT consultants. Furthermore, all the participating companies are private sector manufacturing companies. Future research should investigate other industries, public agencies and NGOs and use data analysis enabling statistical generalizations to enrich the model, and to establish its boundary conditions.

In this study we have investigated IT consultants in acquisitions with one clearly dominant part, not covering the topic in relation to mergers of equals. The more complex merger of equals lies outside the boundaries of the conclusions derived. It is likely that mergers present additional or augmented needs for the use of IT consultants. A merger would be notably larger and likely require more supplementary IT consultants. In addition, a merger is a unique event in the life of an organization. There would be little use in retaining knowledge for a subsequent merger. Both of these factors favour extensive use of IT consultants. Investigating the use of IT consultants in a merger is one of the future avenues for research into agency worker use.

\section{Acknowledgements}

We would like to express our appreciation towards the four case companies and in particular individuals that generously shared their strategic and integration practice with us. We are also thankful towards the track chairs of the track "Methods, Tools and Human Factors in IS/IT Management" at ECIS 2015 as well as the associate editor and the reviewers that gave constructive feedback on an earlier version of this manuscript (Henningsson and Øhrgaard 2015).

\section{References}

Accenture (2002) Getting Information Technology Right is Key to M\&A Successes.

Ackroyd S (2002) The organization of business: applying organizational theory to contemporary change. Oxford University Press,

Alaranta M, Henningsson S Shaping the Post-Merger Information Systems Integration Strategy. In: 40th Hawaii International Conference on System Science Waikoloa, Hawaii, US, 2007-01-05 2007.

Alaranta M, Henningsson S (2008) An approach to analyzing and planning post-merger IS integration: Insights from two field studies. Information Systems Frontiers 10 (3):307-319

Allen L, Jagtiani J, Peristiani S, Saunders A (2004) The Role of Bank Advisors in Mergers and Acquisitions. Journal of Money, Credit \& Banking (Ohio State University Press) 36 (2):197-224

Atkinson J (1985) Flexibility, uncertainty and manpower management, vol 89. Institute of Manpower Studies Brighton,

Atkinson J, Meager N (1986) Is Flexibility Just a Flash in the Pan. Personnel Management (September)

Bandura A, McClelland DC (1977) Social learning theory.

Barkema HG, Schijven M (2008) How do firms learn to make acquisitions? A review of past research and an agenda for the future. Journal of Management 34 (3):594

Barney JS (1991) Firm resources and sustained competitive advantage. Journal of Management:99-120

Beckman CM, Haunschild PR (2002) Network learning: The effects of partners' heterogeneity of experience on corporate acquisitions. Administrative Science Quarterly 47 (1):92-124

Benitez-Amado J, Ray G (2012) Introducing IT-enabled Business Flexibility and IT Integration in the Acquirer's M\&A Performance Equation. 
Pre-edited version of Henningsson \& Øhrgaard: "Consultants In Acquisition IT Integration: A Resource-Based View". Paper forthcoming in Business \& Information Systems Engineering. Refer to the published journal version for citations.

Bharadwaj AS (2000) A Resource-Based Perspective on Information Technology Capability and Firm Performance: an Empirical Investigation. MIS Quarterly 24 (1):169-196

Bingham CB, Davis JP (2012) Learning sequences: their existence, effect, and evolution. Academy of Management Journal 55 (3):611-641

Bloomfield BP, Danieli A (1995) The Role of Management Consultants in the Development of Information Technology: the Indissoluble Nature of SocioPolitical and Technical Skills. Journal of Management Studies 32 (1):23-46

Böhm M, Henningsson S, Leimeister JM, Yetton P, Krcmar H (2011) A Dual View on IT Challenges in Corporate Acquisitions and Divestments. Paper presented at the International Conference on Information Systems, Shanghai, China, December 2011

Bouncken R, Lehmann C, Ratzmann M (2012) Don't bite off more than you can chew. International Journal of Business Research 12 (5)

Bouncken RB, Lehmann C, Ratzmann M (2013) Shades of gray: effect of external work arrangements on firm performance under operational and strategic contingencies. Journal of Business Economics 83 (8):863-900

Bradshaw A, Cragg P, Pulakanam V (2012) Do IS consultants enhance IS competences in SMEs? Electronic Journal Information Systems Evaluation Volume 16 (3)

Bradshaw A, Pulakanam V, Cragg P (2015) Knowledge Sharing in IT Consultant and SME Interactions. Australasian Journal of Information Systems 19

Bryant A, Charmaz K (2007) The Sage handbook of grounded theory. Sage,

Capron L, Dussauge P, Mitchell W (1998) Resource redeployment following horizontal acquisitions in Europe and North America, 1988-1992. Strategic Management Journal 19 (7):631-661

Carlsson SA, Henningsson S, Hrastinski S, Keller C (2011) Socio-technical IS design science research: developing design theory for IS integration management. Information Systems and E-Business Management 9 (1):109-131

Chang JY, Wang ET, Jiang JJ, Klein G (2013) Controlling ERP consultants: Client and provider practices. Journal of Systems and Software 86 (5):1453-1461

Cohen MD, Bacdayan P (1994) Organizational routines are stored as procedural memory: Evidence from a laboratory study. Organization Science 5 (4):554-568

Cohen MD, Burkhart R, Dosi G, Egidi M, Marengo L, Warglien M, Winter S (1996) Routines and other recurring action patterns of organizations: contemporary research issues. Industrial and corporate change 5 (3):653

Cyert RM, March JG (1963) A Behavioral Theory of the Firm. Prentice-Hall, Englewood Cliffs, NJ

Davenport TH (1998) Putting the Enterprise into the Enterprise System. Harward business review $76(4): 121-132$

DePamphilis D (2010) Mergers and acquisitions basics: all you need to know. Academic Press,

DiMaggio PJ, Powell WW (1983) The iron cage revisited: Institutional isomorphism and collective rationality in organizational fields. American Sociological Review: $147-160$

Dubé L, Paré G (2003) Investigating Information Systems with Positivist Case Research. Communication of the AIS 13 (18):233-264

Eisenhardt (1989) Building Theories from Case study Research. Academy of Management Review

Feldman R (2002) Epistemology. Prentice Hall, Upper Saddle River, NJ

Finney S, Corbett M (2007) ERP implementation: a compilation and analysis of critical success factors. Business Process Management Journal 13 (3):329-347

Freitag A, Matthes F, Schulz C (2010) IT Transformation in the Context of Mergers Acquisitions.

Giacomazzi F, Panella C, Pernici B, Sansoni M (1997) Information systems integration in mergers and acquisitions: A normative model. Information \& Management 32:289-302 
Pre-edited version of Henningsson \& Øhrgaard: "Consultants In Acquisition IT Integration: A Resource-Based View". Paper forthcoming in Business \& Information Systems Engineering. Refer to the published journal version for citations.

Grant RM (1991) The resource-based theory of competitive advantage: Implications for strategy formulation. California Management Review 33 (3):114-136

Grant RM (2002) Contemporary Strategic Analysis. Blackwell Publishing, Malden, MA

Gregor S (2006) The nature of theory in information systems. MIS Quarterly 30 (3):611642

Håkansson K, Isidorsson T (2012) Work organizational outcomes of the use of temporary agency workers. Organization Studies 33 (4):487-505

Haleblian J, Devers CE, McNamara G, Carpenter MA, Davison RB (2009) Taking stock of what we know about mergers and acquisitions: A review and research agenda. Journal of Management 35 (3):469

Haunschild P, Miner AS (1995) Interorganizational Learning: The Effect of Outcomes on Learning from the Experience of Others. vol 1377. Graduate School of Business, Stanford University,

Henningsson S (2006) The Role of IS in corporate M\&A-An Examination of IS Research Based on an Integrative Model for M\&A. ICFAI Journal of Mergers \& Acquisitions

Henningsson S Strategic Value of IS Integration in M\&A--The Relation between IS Integration and M\&A as a Tool for Corporate Strategy. In: System Sciences, 2007. HICSS 2007. 40th Annual Hawaii International Conference on, 2007. IEEE, pp 221b-221b

Henningsson S (2015) Learning to acquire: how serial acquirers build organisational knowledge for information systems integration. European Journal of Information Systems 24 (2):121-144

Henningsson S, Carlsson SA (2011) The DySIIM model for managing IS integration in mergers and acquisitions. Information Systems Journal 21 (5):441-476

Henningsson S, Kettinger WJ Late to the Game: Assessing IT Integration Risk After the Acquisition Target has Been Identified. In: System Sciences (HICSS), 2015 48th Hawaii International Conference on, 2015. IEEE, pp 4651-4660

Henningsson S, Øhrgaard C (2015) Acquisition IT Integration: The Roles of Temporary Agency Workers. 23rd European Conference on Information Systems (ECIS) 2015

Henningsson S, Rukanova B, Hrastinski S (2010) Resource dependency in sociotechnical information systems design research. Communication of the AIS 27 (4)

Henningsson S, Yetton P (2011) Managing the IT Integration of Acquisitions by MultiBusiness Organizations. Paper presented at the International Conference on Information Systems 2013, Shanghai, China, December, 2011

Hitt M, King D, Krishnan H, Makri M, Schijven M, Shimizu K, Zhu H (2009) Mergers and acquisitions: Overcoming pitfalls, building synergy, and creating value.

Houseman SN (2003) The benefits implications of recent trends in flexible staffing arrangements. Benefits for the workplace of the future University of Pennsylvania Press, Philadelphia:89-109

Ifinedo P (2008) Impacts of business vision, top management support, and external expertise on ERP success. Business Process Management Journal 14 (4):551-568

Johnston KD, Yetton PW (1996) Integrating information technology divisions in a bank merger Fit, compatibility and models of change. The Journal of Strategic Information Systems 5 (3):189-211

Kalleberg AL, Reynolds J, Marsden PV (2003) Externalizing employment: flexible staffing arrangements in US organizations. Social Science Research 32 (4):525552

KCRA (2014) Global Consulting Index 2014. Report from Kennedy Consulting Research \& Advisory (KCRA). Accessed online: www.consultancy.uk/services/itconsulting [10/01/2016]

Kengelbach J, Klemmer DC, Schwetzler B, Sperling MO, Roos A (2011) How the Top Serial Acquirers Create Value. Boston Consulting Group, 
Klein HK, Myers MD (1999) A Set of Principles for Conducting and Evaluating Interpretive Field Studies in Information Systems. Management Information Systems Quarterly 23 (1):67-93

Ko D-G, Kirsch LJ, King WR (2005) Antecedents of knowledge transfer from consultants to clients in enterprise system implementations. MIS Quarterly:59-85

Kolb DA, Frohman AL (1970) An organization development approach to consulting. Sloan management review 12 (1):51

Lajoux AR (1998) The art of M\&A integration. McGraw-Hill, New York

Larsson R (1993) Case survey methodology: Quantitative analysis of patterns across case studies. Academy of Management Journal 36 (6):1515-1546

Lech P Functional Consultants' Role in Enterprise Systems Implementations. In: Proceedings of the 7 th European Conference on Information Systems Management and Evaluation, 2013.

March JG, Simon HA (1958) Organizations. Wiley, New York

Mehta M, Hirschheim R (2007) Strategic Alignment in Mergers \& Acquisitions: Theorizing IS Integration Decision Making. Journal of the Association for Information Systems 8 (3):143-174

Merali Y, McKiernan P (1993) The strategic positioning of information systems in postacquisition management. Journal of Strategic Information Systems 2 (2):105 124

Miner AS, Bassof P, Moorman C (2001) Organizational improvisation and learning: A field study. Administrative Science Quarterly 46 (2):304-337

Miner AS, Ciuchta MP, Gong Y (2008) Organizational routines and organizational learning. In: Becker M (ed) Handbook of organizational routines. Edward Elgar, Cheltenham, UK, pp 152-186

Mithas S, Ramasubbu N, Sambamurthy V (2011) How Information Management Capability Influences Firm Performance. MIS quarterly 35 (1):237-256

Morsell GA, Deek F, Chakrabarti A (2009) Post-Merger Technology Integration: Influential Organization and Information Systems Factors.

Parada P, Alemany L, Planellas M (2009) The internationalisation of retail banking: Banco Santander's journey towards globalisation. Long Range Planning 42 (5):654-677

Patton MQ (1990) Qualitative evaluation and research methods. SAGE Publications, inc,

Peteraf MA (1993) The cornerstones of competitive advantage: a resource-based view. Strategic Management Journal 14 (3):179-192

Premkumar G (2003) A meta-analysis of research on information technology implementation in small business. Journal of organizational computing and electronic commerce 13 (2):91-121

Quélin B, Duhamel F (2003) Bringing together strategic outsourcing and corporate strategy:: Outsourcing motives and risks. European Management Journal 21 (5):647-661

Ravichandran T, Lertwongsatien C (2005) Effect of information systems resources and capabilities on firm performance: A resource-based perspective. Journal of management information systems 21 (4):237-276

Reynolds P, Yetton P (2015) Aligning business and IT strategies in multi-business organizations. Journal of Information Technology 30:101-118

Robbins SS, Stylianou AC (1999) Post-merger systems integration: the impact on IS capabilities. Information \& Management 36:205-212

Rodgers M (2005) Stay hungry. CIO Magazine (8 April 2005)

Ross JW, Beath CM, Goodhue DL (1996) Develop long-term competitiveness through IT assets. Sloan Management Review 38 (1):31-42

Sanchez R, Mahoney JT (1996) Modularity, flexibility, and knowledge management in product and organization design. Strategic management journal 17 (S2):63-76

Sarker S, Lau F, Sahaj S (2001) Using an adapted grounded theory approach for inductive theory building about virtual team development. The DATA BASE for advances in information systems $32(1): 38-56$ 
Sedera D, Gable GG (2010) Knowledge management competence for enterprise system success. The Journal of Strategic Information Systems 19 (4):296-306

Siakas KV, Balstrup B (2006) Software outsourcing quality achieved by global virtual collaboration. Software Process: Improvement and Practice 11 (3):319-328

Strauss A, Corbin J (1990) Basics of Qualitative Research: Grounded Theory Procedures and Techniques. Sage,

Stylianou AC, Jeffries CJ, Robbins SS (1996) Corporate mergers and the problem of IS integration. Information \& Management 31:203-213

Sudarsanam PS (2003) Creating value from mergers and acquisitions: the challenges: an integrated and international perspective. Prentice Hall,

Tanriverdi H, Uysal VB (2011) Cross-Business Information Technology Integration and Acquirer Value Creation in Corporate Mergers and Acquisitions. Information Systems Research 22 (4)

Tanriverdi Hs, Uysal VBl (2013) When IT capabilities are not scale-free in merger and acquisition integrations: how do capital markets react to IT capability asymmetries between acquirer and target\&quest. European Journal of Information Systems

Thong JY, Yap C-S, Raman K (1994) Engagement of external expertise in information systems implementation. Journal of Management Information Systems 11:209209

Toppenberg G, Henningsson S (2014) Taking stock and looking forward: A scientometric analysis of IS/IT integration challenges in mergers and acquisitions Paper presented at the European Conference on Information Systems (ECIS), Tel Aviv, Israel, June, 2014

Toppenberg G, Henningsson S, Shanks G (2015) How Cisco Systems Used Enterprise Architecture Capability to Sustain Acquisition-Based Growth. MIS Quarterly Executive 14 (4):151-168

Toppenberg GN, Henningsson S (2013) An introspection for the field of IS integration challenges in M\&A. Paper presented at the 19th Americas Conference on Information Systems, Chicago, Illinois, , August 15-17, 2013

Wade M, Hulland J (2004) Review: The Resource-Based View and Information Systems Research: Review, Extension, and Suggestions for Future Research. MIS Quarterly 28 (1):107-142

Wang ET, Chen JH (2006) Effects of internal support and consultant quality on the consulting process and ERP system quality. Decision Support Systems 42 (2):1029-1041

Weber Y, Pliskin N (1996) Effects of information systems integration and organizational culture on a firm's effectiveness. Information and Management 30 (2):81-90

Wernerfelt B (1984) A resource-based view of the firm. Strategic Management Journal 5 (2): $171-180$

Westrup C, Knight F Consultants and Enterprise Resource Planning (ERP) Systems. In: ECIS, 2000. Citeseer, pp 637-644

Wijnhoven F, Spil T, Stegwee R, Fa RTA (2006) Post-merger IT integration strategies: An IT alignment perspective. The Journal of Strategic Information Systems 15 (1):5-28

Wirz P, Lusti M Information technology strategies in mergers and acquisitions: an empirical survey. In: Proceedings of the winter international synposium on Information and communication technologies, 2004. Trinity College Dublin, pp $1-6$

Yetton P, Henningsson S, Bjørn-Andersen N (2013) 'Ready to Acquire': The IT Resources Required for a Growth-by-Acquisition Business Strategy. MIS Quarterly Executive 12 (1):19-35

Yin RK (1994) Case Study Research. Sage Publications, Thousand Oaks

Zollo M (2009) Superstitious learning with rare strategic decisions: Theory and evidence from corporate acquisitions. Organization Science 20 (5):894-908 
Pre-edited version of Henningsson \& Øhrgaard: "Consultants In Acquisition IT Integration: A Resource-Based View".

Paper forthcoming in Business \& Information Systems Engineering. Refer to the published journal version for citations.

Zollo M, Singh H (2004) Deliberate learning in corporate acquisitions: post-acquisition strategies and integration capability in U.S. bank mergers. Strategic Management Journal 25 (13):1233-1257

Zollo M, Winter SG (2002) Deliberate learning and the evolution of dynamic capabilities. Organization Science:339-351 